\section{Preoperative laser} therapy in a patient with resectable bronchogenic carcinoma and severe coronary artery disease

\author{
J Powney, A D Scott, P J M George, \\ R O Feneck, J Wright, N C Barnes
}

\begin{abstract}
A 67 year old man with severe coronary artery disease was found to have a resectable bronchogenic carcinoma. Myocardial revascularisation and lung resection were considered to be unduly hazardous as either separate or combined operations. Preoperative laser therapy, however, enabled the two procedures to be performed in greater safety in the most appropriate sequence.
\end{abstract}

(Thorax 1992;47:1075-1076)

Coronary artery disease and carcinoma of the lung are common diseases that share the risk factor of cigarette smoking. The two conditions may develop concurrently in the same patient and, although myocardial revascularisation and lung resection may be appropriate treatments, they are potentially hazardous when performed as a combined procedure. ${ }^{1}$ It is generally recommended that vein grafting is performed before major non-cardiac surgery. ${ }^{12} \mathrm{We}$ describe the management of a patient with severe coronary artery disease and bronchogenic carcinoma who could not undergo cardiac surgery as an initial procedure because of the combined risks of haemorrhage from the tumour and postoperative pneumonia in the obstructed lung.

\section{Case history}

A 67 year old retired industrial radiographer was admitted to hospital for coronary artery bypass surgery. He was known to be hypothyroid and had been receiving thyroxine replacement therapy for two years. He had smoked 20 cigarettes a day for 25 years but had given up smoking 20 years previously. Coronary angiography had shown severe two vessel disease.

On admission he reported recent haemoptyses and his chest radiograph showed left upper lobe collapse. Fibreoptic bronchoscopy revealed a haemorrhagic polypoid tumour (squamous cell carcinoma) arising from the left upper lobe and obstructing the left main bronchus. Computed tomography of the brain, thorax, and abdomen and an isotope bone scan provided no evidence of metastatic disease. Spirometry indicated a forced expiratory volume in one second $\left(\mathrm{FEV}_{1}\right)$ of 1.51 and a forced vital capacity (FVC) of 2.551 . Although the tumour was resectable, pneumonectomy was considered to be too hazardous in the presence of severe coronary artery disease, and coronary artery surgery was precluded by the combined risks of haemorrhage from the tumour and postoperative pneumonia in the obstructed lung.

In an attempt to improve the patient's fitness for cardiac surgery, endobronchial tumour was resected with a neodymium YAG laser operating at a wavelength of $1.32 \mu \mathrm{m}$ (MBB-Medilas 2, Medizintechnic). Treatment was given at power settings of 10-20 watts in pulses of up to one second. ${ }^{3}$ An airway was restored to the left lower lobe and a large volume of mucus and altered blood was drained; all bleeding points on the tumour bed were then cauterised. Treatment was given under general anaesthesia with full invasive monitoring. Cardiovascular stability was maintained throughout the procedure.

Nine days later vein grafts were applied to the left anterior descending and right circumflex coronary arteries. The operative course was uneventful with no bleeding from the tumour. During the immediate postoperative period he developed complete collapse of the left lung and became hypoxic despite ventilatory support (arterial oxygen tension $\left(\mathrm{PaO}_{2}\right) 7.9 \mathrm{kPa}$ with $80 \%$ oxygen). A fibrin plug occluding the left main bronchus was removed with a fibreoptic bronchoscope. The lower lobe re-expanded with immediate improvement in oxygenation $\left(\mathrm{PaO}_{2} 25 \mathrm{kPa}\right.$ with $70 \%$ oxygen $)$ and he was weaned from ventilatory support. Respiratory function tests performed on the eighth postoperative day showed an $\mathrm{FEV}_{1}$ of 2.51 and an FVC of $3.6 \mathrm{l}$, indicating a considerable improvement.

Pneumonectomy was planned after an interval of four to six weeks. He developed a haematoma in his left leg, however, at the site of his vein surgery, which became infected with methicillin resistant Staphylococcus aureus. His pneumonectomy was postponed for six months until the infection had resolved. Repeat staging confirmed that the tumour was resectable. A left pneumonectomy was performed without complication. Mediastinal lymph nodes were sampled at the time of surgery and were found to be free from tumour. Examination of the resected specimen showed that the hilar glands were also free from tumour, though the bronchial lymph nodes were directly affected; thus he had $\mathrm{T}_{2} \mathrm{~N}_{1} \mathrm{M}_{0}$ stage disease. ${ }^{4}$ The patient has remained well without clinical or radiological signs of recurrence for 27 months. During this time he has been able to lead an active and independent life.

\section{Discussion}

There is general agreement that surgery offers the best prospect of cure in patients with resectable non-small cell carcinoma of the lung. The risks of major non-cardiac surgery are increased substantially, however, in the presence of coronary artery disease. Uncon- 
trolled studies have suggested that these risks may be reduced after myocardial revascularisation $^{25}$ and, although lung resection and coronary artery surgery have been performed successfully as combined procedures, ${ }^{6}$ it has been argued that vein graft surgery should be performed before lung resection. ${ }^{12}$

Cardiac surgery could not be performed as the initial procedure in our patient because anticoagulation would have led to uncontrollable bleeding from the haemorrhagic tumour, and obstruction of the left main bronchus might have predisposed him to pneumonia and would have compounded the loss of respiratory reserve that is known to occur after coronary artery surgery. ${ }^{7}$ This latter problem was apparent when the left main bronchus became temporarily obstructed by a fibrin plug. Despite this complication, laser therapy was judged to have been successful in minimising these risks. Bleeding did not occur during cardiac surgery and resection of the tumour ensured a rapid recovery of ventilatory function after removal of the fibrin plug.

Ideally, pneumonectomy would have been performed shortly after coronary artery surgery. The risk of transferring methicillin resistant Staphylococcus aureus, however, was considered to outweigh the risk of tumour spread. Metastatic disease was not evident at the time of surgery and our patient's predicted five year survival is $40 \%{ }^{4}$

Although endoscopic laser resection has been developed as a palliative treatment, there are now several reports on its value before thoracotomy in patients with operable tumours of the upper airway who presented with impen- ding asphyxia. ${ }^{8-10}$ In these cases the laser restored an adequate airway and thereby provided time in which to plan elective surgery. Our experience shows how laser therapy may also be used to optimise a patient's fitness for cardiac surgery and so facilitate the most appropriate sequence of operative procedures.

We are most grateful to Sister Ophelia Tsang for her assistance with endoscopic laser therapy.

1 Peters RM, Swain JA. Management of a patient with emphysema, coronary artery disease, and lung cancer. $A m$ J Surg 1982;143:701-5.

2 Foster ED, Davis KB, Carpenter JA, Abele S, Fray D. Risk of noncardiac operation in patients with defined coronary disease: the coronary artery surgery study (CASS) registr experience. Ann Thorac Surg 1986;41:42-9.

3 George PJM, Pattison J, Al Jarad N, Tsang O, Whitburn RH, Goldhill DR, et al. Preliminary experience with the $1.32 \mu \mathrm{m}$ neodymium YAG laser in the treatment of tracheobronchial malignancy. Lasers in Medical Science 1991;6:407-13.

4 Mountain CF. A new international staging system for lung cancer. Chest 1986;89(suppl):225-33S

5 Crawford ES, Morris GC, Howell JF, Flynn WF, Moorhead DT. Operative risk in patients with previous coronary artery bypass. Ann Thorac Surg 1978;26:215-20.

6 Dalton MI, Parker TM, Mistrot J, Bricker DL. Concomitant coronary artery bypass surgery and major noncardiac surgery. J Thorac Cardiovasc Surg 1978;75: 621-31.

7 Jenkins SC, Soutar SA, Forsyth A, Keates JRW, Moxham J. Lung function after coronary artery surgery using the internal mammary artery and the long saphenous vein. Thorax 1989;44:209-11.

8 Laforet EG, Berger RL, Vaughan CW. Carcinoma obstructing the trachea: treatment by laser resection. $N$ Engl Med 1976;294:941.

9 George PIM, Garrett CPO, Goldstraw P, Hetzel MR, Ramsay AD. Resuscitative laser photoresection of a tracheal tumour before elective surgery. Thorax 1986; 41:812-3.

10 Shankar S, George PJM, Hetzel MR, Goldstraw P. Elective resection of tumours involving the trachea and main carina following endoscopic laser therapy. Thorax 1990;45: 493-5.

Thorax 1992;47:1076-77

\section{Multiple cystic pulmonary hamartomas}

M Mushtaq, S P Ward, J T Hutchison, J S Mann

\begin{abstract}
A patient with multiple cystic hamartomas presented with a pneumothorax and later developed a cystic myxomatous vaginal polyp. This and three of the cysts were resected. She remains well 13 years later. Multiple cystic hamartomas are uncommon and may be misdiagnosed as pulmonary metastases.
\end{abstract}

\section{(Thorax 1992;47:1076-1077)}

We report a case of multiple cystic hamartomas in which a cystic myxomatous vaginal polyp later developed.

Case report

A 47 year old housewife presented with breathlessness and cough, which had been preceded by a small haemoptysis. She was otherwise well. Examination showed no abnormality but a chest radiograph showed 12 rounded opacities varying from $5 \mathrm{~mm}$ to several centimetres in diameter, suggesting metastases, though her general appearance belied this diagnosis. Some of the nodules were cystic and contained fluid levels. There was a small left pneumothorax (fig 1). Cytological examination of sputum showed no abnormality and tests for hydatid and rheumatoid disease gave negative results. Because of concern that the opacities might represent pulmonary metastases she underwent left thoracotomy, at which a large cyst was found in the greater fissure arising from the upper lobe, with two further cysts arising from the lower lobe. All three were removed by wedge resection.

Macroscopically, two of the cysts had fleshy tissue hanging from their inner walls; the third was almost solid. Microscopically, the appearances were of pulmonary hamartomas consisting of cystic spaces lined by cuboidal and mucus secreting columnar epithelium. The stroma consisted of mesenchyme (fig 2 ).

Over the subsequent 13 years the hamartomas fluctuated considerably in size. Typically they increased in size until cavities developed, often with fluid levels, and then shrank, though some remained unaltered. Antibiotics were often prescribed because of concern about superinfection. 